\title{
Characterization of Leishmania spp. causing cutaneous leishmaniasis in Manaus, Amazonas, Brazil
}

\author{
Leila Ines Camara Coelho • Marcilene Paes • \\ Jorge Augusto Guerra • Maria das Graças Barbosa • \\ Candisse Coelho • Bruna Lima • Maria Edileuza Brito • \\ Sinval Pinto Brandão Filho
}

Received: 22 January 2010 /Accepted: 30 September 2010 /Published online: 12 November 2010

(C) The Author(s) 2010. This article is published with open access at Springerlink.com

\begin{abstract}
In the State of Amazonas, American tegumentary leishmaniasis is endemic and presents a wide spectrum of clinical variability due to the large diversity of circulating species in the region. Isolates from patients in Manaus and its metropolitan region were characterized using monoclonal antibodies and isoenzymes belonging to four species of the parasite: Leishmania (Viannia) guyanensis, 73\% (153/ 209); Leishmania (Viannia) braziliensis, 14\% (30/209); Leishmania (Leishmania) amazonensis, 8\% (17/209); and Leishmania (Viannia) naiffii, 4\% (9/209). The most prevalent species was $L$. (V.) guyanensis. The principal finding of this study was the important quantity of infections involving more than one parasite species, representing $14 \%$ $(29 / 209)$ of the total. The findings obtained in this work regarding the parasite are further highlighted by the fact that
\end{abstract}

\footnotetext{
L. I. Camara Coelho $(\bowtie) \cdot$ M. Paes $\cdot$ J. A. Guerra

Gerencia de Leishmanioses,

Funbdação de Medicina Tropical do Amazonas,

Manaus, Brazil

e-mail: liarccoelho@yahoo.com.br
}

\section{M. d. G. Barbosa}

Entomologia, Fundação de Medicina Tropical do Amazonas,

Manaus, Brazil

C. Coelho

Medicina, Universidade Federal do Amazonas,

Manaus, Brazil

B. Lima

Leishmanioses, Centro de Pesquisa Aggeu Magalhães,

Recife, Brazil

M. E. Brito · S. P. Brandão Filho

Fiocruz, Centro de Pesquisa Aggeu Magalhães,

Recife, Brazil these isolates were obtained from clinical samples collected from single lesions.

\section{Introduction}

Epidemiologically, American tegumentary leishmaniasis (ATL) is considered an enzootic disease aggravated by several factors. In the State of Amazonas, Brazil, four species of Leishmania are responsible for the disease in humans, involving clinical presentation in the cutaneous and mucosal forms: Leishmania (Viannia) guyanensis, Leishmania (Viannia) braziliensis, Leishmania (Viannia) naiffii, and Leishmania (Leishmania) amazonensis.

In the last 12 years (1994 to 2005), an annual mean of 30,383 cases of tegumentary leishmaniasis have been registered. In 2006, 22,097 cases were notified and in 2007, 20,737 cases, which is an expressive decrease in the number of cases registered in previous years (http://www4.ensp.fiocruz.br/Leishmaniose/ situacao-da-lt-no-brasil/). In the State of Amazonas, 12,005 cases were registered in the same period, with a mean incidence rate of 86.77; however, in 2003, the rate was 121.03, with 3,174 cases, $60.18 \%$ in the city of Manaus (Guerra et al. 2006). The cases are concentrated in the metropolitan region of Manaus, with around 600 cases per year, according to database of the Disease Notification Information System (Sistema de Informação de Agravos de Notificação, SINAN), run by the Secretary for Health and Safety (Secretaria de Vigilância em Saúde) of the Ministry of Health (http://dtr2004.saude.gov.br/ sinanweb/tabnet/tabnet?sinan/lta/bases/ltabr.def).

The classical taxonomic methods used for Leishmania classification and typing are based on a panel of specific monoclonal antibodies and an electrophoretic profile of isoenzymes (MLEE). Other methods based on DNA 
detection and sequencing are also used. Due to the abundance of the Amazon biodiversity, some authors have suggested that other species may exist in the region, including species not yet characterized that could also be responsible for infections in humans, given that flagellated forms of the parasite are frequently observed in mammals and phlebotomines in the region (Grimaldi et al. 1991; Silveira et al. 2004).

The human cases of ATL in this region are mostly verified in the adult population who are involved in work related to agricultural activities, such as the extraction of rosewood oil and cassava cultivation, as well as other subsistence crops like beans and corn. The majority of the autochthonous cases are attended at the Manaus Tropical Medicine Institute Foundation (Fundação Instituto de Medicina Tropical de Manaus). Precise categorical identification of Leishmania spp. is fundamental to understanding the epidemiology of the disease and improving current knowledge concerning its pathology, the use of chemotherapy, and for implementing control measures.

Specific monoclonal antibodies have been used for several years to identify Leishmania spp. (McMahon-Pratt et al. 1986; Grimaldi et al. 1987, 1991; Shaw and Lainson 1987, 1989; Barral-Neto et al. 1986; Barral 1988) and have demonstrated high and consistent specificity in the characterization of species of this parasite, unequivocally proving its identification (Grimaldi and Tesh 1993; Grimaldi and McMahon-Pratt 1996; Romero et al. 2002a, b, 2005; Abbas and Lichtman 2005).

The electrophoretic mobility of enzymes (multilocus enzyme electrophoresis, MLEE) is another tool for categorically characterizing this parasite, revealing polymorphisms that express phenotypes of population variations and taxonomically classify the different species of Leishmania (Cupolillo et al. 1994, 1998; Saravia et al. 1998).

In the last few years, polymerase chain reaction (PCR) has been widely used as a parasitological diagnostic test on clinical samples of patients with ATL, due to its high sensitivity (Barker et al. 1991; Degrave et al. 1994) and to detect natural infection in phlebotomine vectors and reservoir hosts (Pita-Pereira et al. 2005; Brandão-Filho and Shaw 2006). Its use has demonstrated greater sensitivity in relation to the conventional method of diagnosis based on direct parasitological exam under an optic microscope (Isaza et al. 1999; Rodrigues et al. 2002; Weigle et al. 2002).

This study aimed to characterize the species of Leishmania isolated in patients with ATL originating from the city of Manaus and its metropolitan region, attended at the outpatient clinic of the Amazonas Tropical Medicine Foundation (Fundação de Medicina Tropical do Amazonas, FMTAM) in Manaus, relating patients' location of origin to the species of parasite detected.

\section{Material and methods}

\section{Patients}

The individuals included in the study spontaneously sought attendance at the FMTAM, a reference center for tropical diseases in the State of Amazonas, Brazil, to obtain a clinical and laboratorial diagnosis of ATL. The patients all originated from the city of Manaus and municipalities of the metropolitan region: Itacoatiara, Manacapuru, Novo Airão, Rio Presidente Figueiredo, and Preto da Eva. The study was submitted to and approved by the Ethics in Research Committee of the FMTAM, under no. 1830/2006. All the participants signed a term of free and informed consent.

Parasitological exam

All the patients involved in the study were submitted to direct exam by scarification of the margins of a single typical lesion, followed by Giemsa staining, in accordance with Ministry of Health directives ( Brasil Ministério da Saúde and Fundação Nacional de Saúde 2000, 2002), to visualize the amastigotes under optic microscopy.

\section{Isolation of Leishmania spp}

Clinical samples obtained by fine needle aspiration biopsy of the margins of cutaneous lesions or fragments obtained by 3-4-mm punch biopsy, in accordance with the method described by Marzochi et al. (1993) and Romero et al. (2002a, b), were inoculated in Novy-Neal-Nicolle (NNN) culture medium, first described by Novy-Neal and Nicolle (1909) and modified by Shaw and Lainson (1981 and Shaw et al. (1989). The cultures were examined every 3 days for a maximum period of 30 days to detect promastigotes under optic microscopy.

Preparation of the parasitic mass for parasite characterization

The parasites were transferred from modified NNN culture medium to Schneider's Drosophila medium (S9895, Sigma) containing 20\% fetal bovine serum (FBS) and antibiotics $(50 \mathrm{mg} / \mathrm{ml}$ of streptomycin and $100 \mathrm{U} / \mathrm{ml}$ of penicillin or $80 \mathrm{mg} / \mathrm{ml}$ of gentamicin). They were observed for 3 to 5 days until they achieved the stationary growth phase. Once this occurred, an aliquot of the culture was added to $4 \%$ formaldehyde diluted 1:1,000 in phosphate-buffered solution (PBS), followed by parasite counts in a Neubauer chamber at concentrations between $1 \times 10^{5}$ and $1 \times 10^{7}$. Next, they were washed twice in PBS, $\mathrm{pH} 7.2$, and $0.01 \mathrm{M}$ EDTA and centrifuged for $10 \mathrm{~min}$ at $2,500 \mathrm{rpm}$, in 
accordance with Evans et al. (1984; Evans 1989; Brasil Ministério da Saúde and Fundação Nacional de Saúde 2000). The parasite mass was separated into aliquots, which were frozen and stored at $-20^{\circ} \mathrm{C}$ while awaiting characterization.

Analysis of monoclonal antibodies (serodemes)

Preparation of the parasites for monoclonal typing was performed in accordance with laboratorial protocol L30/181/ 4 of the WHO Special Program for Research and Training on Tropical Diseases (WHO/TDR, 2002). Indirect immunofluorescence reaction on monoclonal antibodies was performed using the following panel of 14 specific monoclonal antibodies: L. (V.) braziliensis (D3-complex), L. (V.) braziliensis (B12,16,18), L. (V.) guyanensis/panamensis (B19,4,5,7,11), L. (L.) amazonensis/venezuelensis (M3,7,8,P9), and L. (V.) naiffi (B1). Series D and B react with species of the subgenus Viannia and series $\mathrm{M}$ and $\mathrm{P}$ react with species of the subgenus Leishmania. The following international standard strains were used as positive controls: $L$. (V.) guyanensis (MHOM 4147), L. (V.) braziliensis (MHOM 2903), L. (L.) amazonensis (Ph8 and MHOM 81889), and $L$. (V.) naiffii (MHOM 5533).

Characterization by isoenzyme electrophoresis

Analysis of electrophoretic mobility using isoenzymes (MLEE) was performed using a system consisting of seven enzymes. Electrophoresis was performed on agarose gel and the allelic variations were tested for the following enzymes: isomerases: 6-phosphogluconate dehydrogenase (6PGDH, E.C.1.1.1.44), mannose phosphate isomerase (MPI, E.C.5.3.1.8), glucophosphate isomerase (GPI, E. C.5.3.1.9); transferases: phosphoglucomutase (PGM, E. C.2.7.5.1); oxidoreductases: glucose-6-phosphate dehydrogenase (G6PDH, E.C.1.1.1.49), isocitrate dehydrogenase (IDH-NADP, E.C.1.1.1.42); and lyases: aconitase (ACON, E.C.4.2.1.3). The method was performed in accordance with the conditions described by Cupolillo et al. (1994, 1998). Each isolate was compared to the WHO reference species mentioned above (WHO/TDR, 2002).

DNA detection by polymerase chain reaction (PCR)

DNA isolation was performed using the Genomic Prep Cells and Tissue DNA Isolation kit (Amershan Biociences), in accordance with the manufacturer's recommendations. The PCR test for Leishmania (Viannia) spp. DNA was performed in accordance with De Bruijin and Barker (1992), using the kDNA minicircle region as the target and specific primers for the subgenus Viannia: B1-GGGGTTGGTGTAATATAGTGG $5^{\prime}$ to $3^{\prime}$ and B2-CTAATTGTGCACGGGGAGG $5^{\prime}$ to $3^{\prime}$. For the subgenus Leishmania (Leishmania) spp., the target was also the kDNA minicircle region and the primers were: RV1, (GC)(GC)(GC)CC(A/C)CTAT(A/T)TTACACCAACCCC 5' to $3^{\prime}$ and RV2, GGGGAGGGGCGT $5^{\prime}$ to $3^{\prime}$, in accordance with Le Fichoux et al. (1999). The positive controls used were the same as the WHO reference strains used in the characterization by monoclonal antibodies and enzymes.

\section{Results}

A total of 209 Leishmania spp samples were isolated and characterized. The majority of the isolates, $61.2 \%(128 /$ 209), originated from patients who resided in Manaus, with $38.8 \%(81 / 209)$ residing in the metropolitan regions (Fig. 1). The direct parasitological exam by scarification was positive in $85.2 \%(178 / 209)$ of cases.

Men were predominant $(77 \%(161 / 209))$, and the mean patient age was 31.6 years old (Table 1$)$.

Four parasite species were identified: $L$. (V.) guyanensis, 73.2\% (153/209); L. (V.) braziliensis, 14.4\% (30/209); L. (L.) amazonensis, 8.1\% (17/209); and L. (V.) naiffii, 4.3\% (9/209). However, of the total, $13.9 \%(29 / 209)$ of patients presented mixed infections: $4.8 \%(10 / 209)$ involving $L .(V$. guyanensis and L. (V.) braziliensis; 4.8\% (10/209) involving $L$. (V.) guyanensis and $L$. (V.) naiffi; $1.4 \%(3 / 209)$ involving $L$. (V.) guyanensis, $L$. (V.) braziliensis, and $L$. $(V$. naiffi; $1.4 \%$ (3/209) involving $L$. (V.) guyanensis, $L$. $(V$. braziliensis, and $L$. (L.) amazonensis; $0.5 \%$ (1/209) involving $L$. (V.) guyanensis and L. (L.) amazonensis; $0.5 \%$ (1/ 209) involving $L$. (V.) guyanensis, L. (V.) braziliensis, and L. (L.) amazonensis; $0.5 \%(1 / 209)$ involving $L$. (V.) guyanensis, $L$. (V.) naiffi, and $L$. (L.) amazonensis; and $0.5 \%$ (1/209) involving $L$. (V.) guyanensis, $L$. (V.) braziliensis, $L$. (V.) naiffi, and $L$. (L.) amazonensis (Table 2).

Characterization by MLEE revealed a greater frequency of alleles of $6 \mathrm{PGDH}(45.0 \%, 94 / 209)$, followed by PGM (24.9\%, 52/209), G6PDH (23.0\%, 48/209), GPI $(21.5 \%$, 45/209), ACON (19.1\%, 40/209), IDH-NADP (16.7\%, 35/ $209)$, and MPI $(1.9 \%, 4 / 209)$. Quality control was achieved by randomly testing $15 \%$ of the isolates, performed by the reference laboratory for Leishmania typing and Leishmania spp. collection (CLIOC/FIOCRUZ), and the results were in agreement.

Randomly selected samples from among the isolates characterized by monoclonal antibodies and MLEE (32.5\%; 68/209) were submitted to the PCR test. Among these, $21.5 \%(45 / 209)$ were positive for the subgenus Viannia target and $11.0 \%$ (23/209) for the subgenus Leishmania.

The mean time of disease evolution was 33 days. No significant differences were observed among the patients who were identified with mixed infections compared to the disease evolution time in the remaining patients infected by a single species. The only patient typed as a carrier of four 
Fig. 1 Locations of case occurrence in Manaus and its metropolitan regions

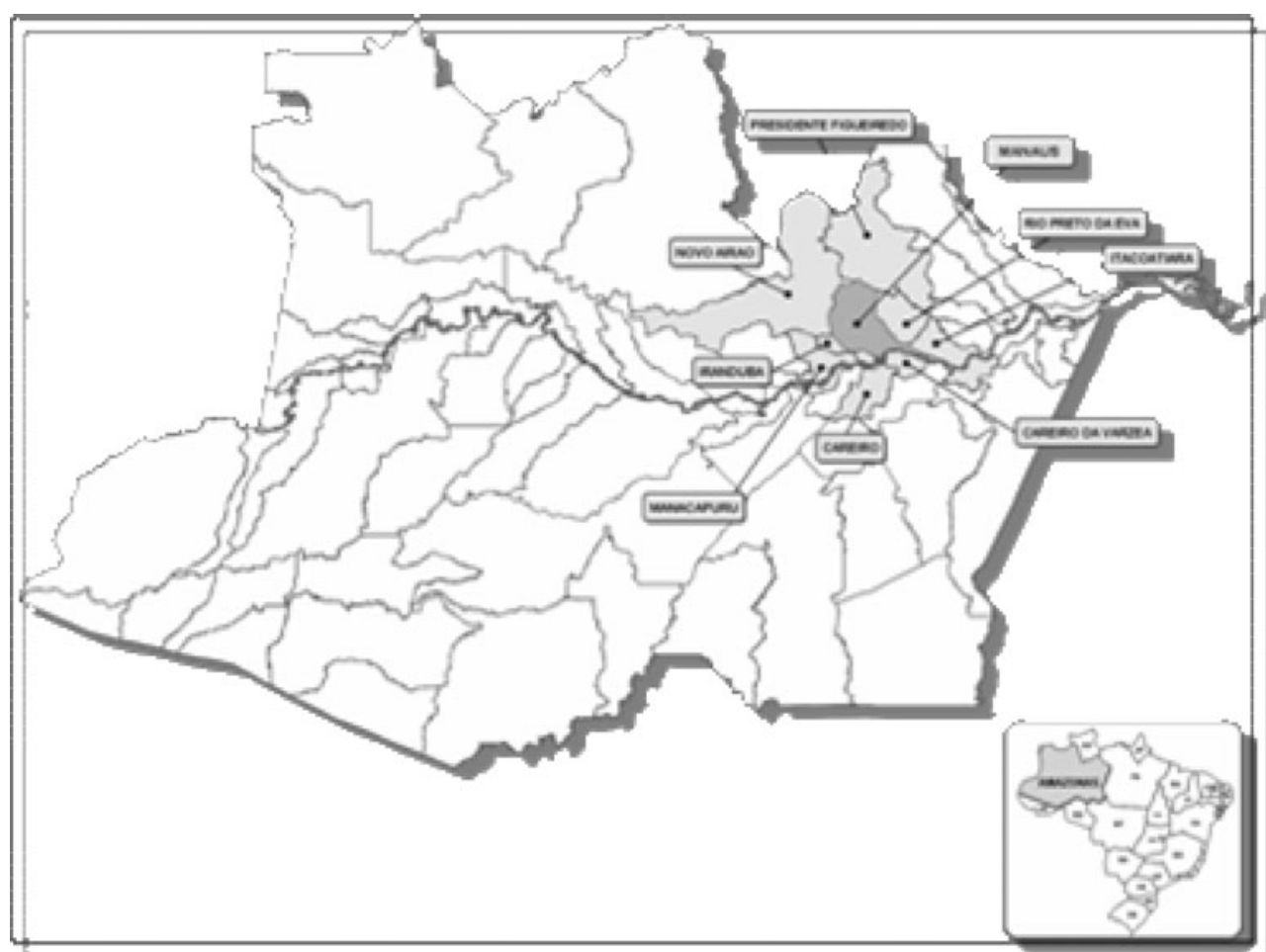

Leishmania spp. species was a male, 36 years of age, and a farmer, who presented five typical lesions on one leg, one hand, and on both arms.

\section{Discussion}

American tegumentary leishmaniasis is endemic in the State of Amazonas, where it presents a wide spectrum of clinical variability due to the diversity of species circulating in the region. The most prevalent species is $L$. $(V$. $)$ guyanensis, showing greatest concentration in the area of the city of Manaus and the surrounding metropolitan region.

The findings obtained in this study regarding the parasite are in agreement with those obtained by (Naiff 1998) and Romero et al. (2000, 2001a, 2002a, 2005).

Table 1 Distribution of ATL cases according to gender and age

\begin{tabular}{lcc}
\hline Age group & M & \multicolumn{2}{c}{ F } \\
\hline $0-10$ & 11 & 9 \\
$11-20$ & 61 & 15 \\
$21-30$ & 69 & 26 \\
$31-40$ & 43 & 17 \\
$41-50$ & 38 & 5 \\
$51-60$ & 24 & 5 \\
$61-70$ & 5 & 2 \\
$>71$ & 2 & 3 \\
Mean & 31.63 & 10.25 \\
\hline
\end{tabular}

The most relevant finding of this work was the high percentage of patients who presented mixed infections, particularly when considering that the isolates were obtained from clinical samples taken from a single lesion. This further corroborates the reports of other researchers, including Shaw (1985), Shaw and Lainson (1987), Shaw et al. (1989), Grimaldi and McMahon-Pratt (1996), Strelkova et al. (1990a, b, 1997), Saravia et al. (1998), Vray (1998), Bastrenta et al. (2003), and Brito et al. (2009), which were conducted in several regions in Brazil and in other countries. It should be noted that the findings reported by Shaw (1985) were obtained from clinical samples collected from more than one lesion per patient.

These data also elucidate the diversity and heterogeneity of the disease and the complexity of the transmission cycles

Table 2 Distribution of cases of mixed infections according to Leishmania spp. species

\begin{tabular}{|c|c|c|}
\hline Parasite species & $\begin{array}{l}\text { Number } \\
\text { of cases }\end{array}$ & Percentage \\
\hline L. (V.) guyanensis e L. (V.) braziliensis & 10 & 4.78 \\
\hline L. (V.) guyanensis e $L .(V$.$) naiffi$ & 10 & 4.78 \\
\hline L. (V.) guyanensis e L. (L.) amazonensis & 1 & 0.48 \\
\hline L.(V.) guyanensis, $L .(V$.$) braziliensis e L .(V$.$) naiffi$ & 3 & 1.44 \\
\hline $\begin{array}{l}\text { L. }(V .) \text { guyanensis, } L .(V .) \text { braziliensis e } L .(L .) \\
\text { amazonensis }\end{array}$ & 3 & 1.44 \\
\hline $\begin{array}{l}\text { L. (V.) guyanensis, } L .(V .) \text { naiffi e } L .(L .) \\
\text { amazonensis }\end{array}$ & 1 & 0.48 \\
\hline $\begin{array}{l}\text { L. (V.) guyanensis, L.(V.) braziliensis, } L . \\
(V .) \text { naiffi e } L .(L .) \text { amazonensis }\end{array}$ & 1 & 0.48 \\
\hline
\end{tabular}


in this region in relation to the phlebotomines and reservoir hosts involved. The heterogeneity observed in mixed infections involving $L$. (V.) guyanensis, L. (V.) braziliensis, $L$. (V.) naiffii, and $L$. (L.) amazonensis and their capacity for concomitant survival while causing ATL, contrasts with the homogeneity of parasites isolated in other regions, particularly in the northeast and southeast of Brazil (Brito et al. 1993; Brandão-Filho et al. 2003; Cupolillo et al. 2003). Brito et al. (2009) verified 10 different zymodemes in isolates of L. (V.) braziliensis and Leishmania (Viannia) shawii, originating from the Atlantic Forest zone in Pernambuco, northeastern Brazil, confirming the coexistence of two species that divided the same ecosystem and interfered in the natural genetic polymorphism of the Leishmania spp. populations in this endemic region.

The results of typing using monoclonal antibodies were consistent with characterization by MLEE. Cases of cutaneous leishmaniasis can achieve cure spontaneously; however, in this study, all the patients were treated. Since disease notification is compulsory, all the cases were registered in the SINAN. Mixed infections have been reported in other diseases caused by different protozoans. In cases of malaria, up to $27.0 \%$ (Lorenzetti et al. 2008) of mixed infections have been verified in certain areas, demonstrating the coexistence of two species (Plasmodium falciparum and Plasmodium vivax) which contributes to increased virulence, transmissibility, and resistance to drugs due to intrahost competition (Havyliuk and Ferreira, 2009).

Characterization of the origin of the isolates provided detailed information regarding the distribution of the diversity of circulating species in Manaus, including the predominance of $L$. $(V$.) guyanensis. The municipalities of the metropolitan area that form AM010 (Rio Preto da Eva and Itacoatiara) presented a greater frequency of $L$. (V.) braziliensis and this species in association with other species. Although all the patients responded to treatment, even when successful, cutaneous leishmaniasis can still relapse or even evolve to the mucosal form. According to both Schubach et al. (1988) and Mendonça et al. (2004), the parasite can remain latent, so continuous follow-up is necessary in these patients.

Romero et al. (2001a, b) observed a casuistic of clinical characteristics in patients with ATL associated with $L$. $(V$.) guyanensis and correlated lesion size and numbers, which presented a larger number of lesions with smaller diameters than those who were infected by $L$. (V.) braziliensis. Multiple lesions can be explained by the occurrence of simultaneous bites by several infected insects and/or metastasis by hematogenic route (Naiff et al. 1999). Similar observations were made in this work, in agreement with Naiff et al. (1999), such that in patients presenting mixed infection, variations in lesion size and numbers also occurred.

Campbell-Lendrum et al. (2001) observed a change in the epidemiological pattern of leishmaniases transmission in several South American countries, with important domiciliation of the vectors in Venezuela, Peru, Bolivia, and Brazil. Analysis of these data demonstrates that disappearance of the disease in South America is not likely to occur, since domiciliation of the vector had already established and was currently evident in various Brazilian regions (Brandão-Filho et al. 1999).

The vectors Lutzomyia umbratilis and Lutzomyia anduzei are considered the principal and second most important transmitters in this region of Manaus, respectively (Guerra et al. 2006), while in a casuistic of 65 patients, Naiff et al. (1999) determined that $91 \%$ presented cutaneous lesions exclusively caused by $L$. (V.) guyanensis. They also verified an increase in the occurrence of cases in the rainy season (May-October) due to the high vector population density.

Further studies are required to confirm whether a tendency for urbanization exists in the expansion of the disease and in relation to the findings regarding mixed infections verified in this work. Characterizing the current status of the phlebotomine fauna and reservoir hosts responsible for the maintenance of the zoonotic cycle of American tegumentary leishmaniasis in the region is fundamental in order to assist in the adoption of measures directed at the surveillance and control of this important endemic disease in the State of Amazonas.

Acknowledgements The authors would like to thank Maria Rita Teixeira and Mr. Juracy from INPA for their assistance with the laboratorial tasks, CPqLMD/FIOCRUZ for the inter-institutional postgraduation program, WHO/TDR for providing the monoclonal antibodies, and FMTAM for their technical support.

Open Access This article is distributed under the terms of the Creative Commons Attribution Noncommercial License which permits any noncommercial use, distribution, and reproduction in any medium, provided the original author(s) and source are credited.

\section{References}

Abbas AK, Lichtman AH (2005) Imunologia celular e molecular. Saunders Elsevier, 5a Edição

Barker D, Bruijn M, Eresh S et al (1991) Diagnosis of leishmaniasis using PCR on parasite DNA extracted from human biopsy samples, aspirates, sandflies and culture. Mem Inst Oswaldo Cruz 86((Suppl I)):73-74

Barral AM (1988) Caracterização fenotípica e genotípica de cepas de Leishmania isoladas das diversas formas clínicas de leishmaniose humana no Estado da Bahia. Thesis. Universidade Federal da Bahia

Barral-Neto M, Badaró R, Barral A et al (1986) Imunologia da Leishmaniose Tegumentar. Rev Soc Bras Med Trop 19:175191

Bastrenta B, Mita N, Buitrago R, Vargas F et al (2003) Human mixed infections of Leishmania spp. and Leishmania-Trypanosoma cruzi in a sub Andean Bolivian area: identification by polymerase chain reaction/hybridization and isoenzyme. Mem Inst Oswaldo Cruz 98:255-264 
Brandão-Filho SP, Shaw JJ (2006) Molecular tools versus parasite isolation for evaluating the hosts of Leishmania braziliensis. Trends Parasitol 22:500-512

Brandão-Filho SP, Campbell-Lendrum D, Brito MEF et al (1999) Epidemiological surveys confirm an increasing burden of cutaneous leishmaniasis in north-east Brazil. Trans R Soc Trop Med Hyg 93:488-494

Brandão-Filho SP, Brito MEF, Carvalho FG et al (2003) Wild and synantropic hosts of Leishmania (Viannia) braziliensis in the endemic cutaneous leishmaniasis locality of Amaraji, Pernambuco State, Brazil. Trans Rev Soc Trop Med Hyg 97:291-296

Brasil Ministério da Saúde (2007) Manual de vigilância da Leishmaniose Tegumentar Americana. Brasília, DF

Brasil Ministério da Saúde, Fundação Nacional de Saúde (2000) Manual de controle da leishmaniose tegumentar americana. Brasília, DF

Brasil Ministério da Saúde, Fundação Nacional de Saúde (2002) Guia de Vigilância Epidemiológica. Brasília 2:501-524

Brito MEF, Brandão-Filho SP, Sales NRS et al (1993) Human cutaneous leishmaniasis due to a new enzymatic variant of Leishmania (Viannia) braziliensis occurring in Pernambuco, Brazil. Mem Inst Oswaldo Cruz 88:633-634

Brito MEF, Andrade MS, Mendonça MG et al (2009) Species diversity of Leishmania (Viannia) parasites circulating in an endemic area for cutaneous leishmaniasis located in the Atlantic rainforest of northeastern Brazil. Trop Med Inter Heal 14:1-9

Campbell-Lendrum D, Dujardin JP, Martinez E et al (2001) Domestic and peridomestic transmission of American cutaneous leishmaniasis: changing epidemiological patterns present new control opportunities. Mem Inst Oswaldo Cruz 96:159-162

Cupolillo E, Grimaldi G Jr, Momen H (1994) A general classification of New World Leishmania using numerical zymotaxonomy. Am J Trop Med Hyg 50:250-311

Cupolillo E, Momen H, Grimaldi G Jr (1998) Genetic diversity in natural populations of New World Leishmania. Mem Inst Oswaldoaldo Cruz 93(5):663-668

Cupollilo E, Ibrahim LR, Toaldo CB et al (2003) Genetic polymorphism and molecular epidemiology of Leishmania (Viannia) braziliensis from different host and geographic areas in Brazil. J. Clin. Microbiol. 41(7):3126-3132

Degrave W, Fernandes O, Campbell D et al (1994) Use of molecular probes and PCR for detection and typing of Leishmania - a minireview. Mem Inst Oswaldo Cruz 89:463-469

De Bruijin MH, Barker DC (1992) Diagnosis of New World Leishmaniasis: specific detection of species of the Leishmania braziliensis complex by amplification of kinetoplast DNA. Acta Trop 52:45-58

Evans DA (1989) Solutions culture medium. In: Handbook on isolation, characterization and cryopreservation of Leishmania, vol 198. World Heath Organization, Geneva, pp 28-32

Evans DA, Lanham SM, Baldwin CI et al (1984) The isolation and isoenzyme characterization of Leishmania braziliensis subsp. from patients with cutaneous leishmaniasis acquired in Belize. Trans R Soc Trop Med Hyg 78:35-42

Grimaldi G Jr, Tesh RB (1993) Leishmaniasis of the new world: current concepts and implications for future research. Clin Microbiol Rev 6:230-250

Grimaldi G Jr, McMahon-Pratt D (1996) Monoclonal antibodies for the identification of new world Leishmania species. Mem Inst Oswaldo Cruz 91:137-142

Grimaldi G Jr, McMahon-Pratt D, Jr D (1987) Identification and distribution of new world Leishmania species characterized by serodemes analysis using monoclonal antibodies. Am J Trop Med Hyg 32:270-287
Grimaldi G Jr, Momen H, Naiff RD et al (1991) Characterization and classification of Leishmanial parasites from humans, wild mammals and sand flies in the Amazon region of Brazil. Am J Trop Med Hyg 44:645-661

Guerra JOA, Ribeiro JAS, Coelho LIARC et al (2006) Epidemiologia da leishmaniose tegumentar na Comunidade São João, Manaus, Amazonas, Brasil. Cad Saúde Pública Rio de Janeiro 22:2319-2327

Havyliuk T, Ferreira MU (2009) A closer look at multiple-clone Plasmodium vivax infections: detection methods, revalence and consequences. Mem Inst Oswaldo Cruz 104:67-73

Isaza DM, Restrepo BN, Arboleda M et al (1999) La leishmaniasis: conocimientos y praticas en poblaciones de la Costa del Pacífico de Colombia. Rev Panam Salud Pública 6:177-184

Le Fichoux Y, Quaranta JF, Aufeuvre JF et al (1999) Occurrence of Leishmania infantum Parasitemia in asymptomatic blood donors living in an area of endemicity in southern France. J Clin Microbiol 37:1953-1957

Lorenzetti A, Fornazari PA, Bonini-Domingos AC et al (2008) Mixed Plasmodium faciparum infections and its clinical implications in four areas of the Brazilian Amazon region. Acta Trop 107:8-12

Marzochi MC, Teixeira PC, Marzochi KB et al (1993) Vacuum aspiratory puncture system for Leishmania culturing, isolation and transport. Preliminary report. Rev Inst Med Trop São Paulo 35:301-303

McMahon-Pratt D, David JR (1981) Monoclonal antibodies that distinguish between new world species of Leishmania. Nature 291:581-583

McMahon-Pratt D, Bennett E, Grimaldi G Jr et al (1986) Subspecies and species antigens of Leishmania mexicana characterized by monoclonal antibodies. J Immunol 134:1935-1940

Mendonça MG, de Brito ME, Rodriguez EH et al (2004) Persistence of Leishmania parasites in scars after clinical cure of american cutaneous leishmaniasis: is there a sterile cure? J Infect Dis 189:1018-1023

Naiff MF (1998) Estudo demográfico da Leishmaniose Tegumentar na Amazônia e mapeamento geográfico dos agentes etiológicos na região. Dissertation, Instituto Oswaldo Cruz

Naiff MF, Cupolillo E, Naiff R et al (1999) Leishmaniose tegumentar na amazônia: distribuição geográfica dos agentes etiológicos na região. Rev Soc Bras Med Trop 32:243

Pita-Pereira D, Alves CR, Souza MB et al (2005) Identification of naturally infected Lutzomyiaintermedia and Lutzomyiamigonei with Leishmania (Viannia) braziliensis in Rio de Janeiro (Brazil) revealed by a PCR multiplex non-isotopic hybridisation assay. Trans R Soc Trop Med Hyg 99:905-913

Rodrigues EH, Brito MEF, Mendonça MG et al (2002) Evaluation of PCR for diagnosis of American cutaneous leishmaniasis in an area of endemicity in northeastern Brazil. J Clin Microbiol 40:3572-3576

Romero GAS, Ishikawa E, Shaw JJ et al (2000) Prevalência da infecção por Leishmania (Viannia) braziliensis em pacientes com Leishmaniose cutânea procedentes da calha norte do rio Amazonas atendidos em Centro de Referência em Manaus. Amazonas. Rev Soc Bras Med Trop 33:321

Romero GAS, Guerra MV, Paes MG et al (2001a) Comparison of cutaneous leishmaniasis due to Leishmania (Viannia) braziliensis and L. (V.) guyanensis in Brazil: clinical findings and diagnostic approach. Clin Infect Dis 32:1304-1312

Romero GA, Guerra MV, Paes MG et al (2001b) Sensitivity of the polymerase chain reaction for the diagnosis of cutaneous leishmaniasis due to Leishmania (Viannia) guyanensis. Acta Trop 79:225-229

Romero GAS, Ishikawa E, Cupolillo E et al (2002a) The rarity of infection with Leishmania (Viannia) braziliensis among patients from the Manaus region of Amazonas state, Brazil, who have cutaneous leishmaniasis. Ann Trop Med Parasitol 96:131-136 
Romero GAS, Ishikawa E, Cupollilo E et al (2002b) Identification of antigenically distinct populations of Leishmania (Viannia) guyanensis from Manaus, Brazil, using monoclonal antibodies. Acta Trop 82:25-29

Romero GAS, Orge MG, Guerra MV et al (2005) Antibody response in patients with cutaneous leishmaniasis infected by Leishmania (Viannia) braziliensis or Leishmania (Viannia) guyanensis in Brazil. Acta Trop 93:49-56

Saravia NG, Segura I, Holguin AF et al (1998) Epidemiologic, genetic, and clinical associations among phenotypically distinct populations of Leishmania (Viannia) in Colombia. Am J Trop Med Hyg 56:86-94

Schubach A, Marzochi MC, Cuzzi-Maya T et al (1988) Cutaneous scars in american tegumentary leishmaniasis patients: a site of Leishmania (Viannia) braziliensis persistence and vaiability eleven years after antimonial therapy and clinical care. J Trop Med Hyg 58(6):824-827

Shaw JJ (1985) Taxonomia do gênero Leishmania Conceito tradicionalista $\mathrm{X}$ conceito moderno. Ann Bras Dermatol 60:67-72

Shaw J, Lainson R (1981) The in vitro cultivation of members of the Leishmania braziliensis complex. Trans Roy Soc Trop Med and Hyg 75:127-128

Shaw JJ, Lainson R (1987) Evolution, classification and geografical distribution. In: Peters W, Killick-Kendrick R (eds) The leishmaniasis in biology and medicine, vol 1. Academic Press, London, pp 1-120

Shaw JJ, Ishikawa EA, Lainson R (1989) A rapid sensitive method of the identification of Leishmania with monoclonal antibodies using fluorescein-labelled avidin. Trans R S Trop Med and Hyg 83:783-784

Silveira FT, Lainson R, Shaw JJ et al (1984) Leishmaniose Cutânea na Amazônia, registro do primeiro caso humano de infecção mista, determinado por duas espécies distintas de Leishmânias: Leishmania braziliensis e Leishmania mexicana amazonensis. Rev Inst Med Trop São Paulo 26:272-275

Silveira FT, Lainson R, Corbett CE (2004) Clinical and immunopathological spectrum of American cutaneous leishmaniasis with special reference to the disease in Amazon, Brazil. Mem Inst Oswaldo Cruz 99:239-251

Strelkova MV, Shurkhal AV, Eliseve LN et al (1990a) Isoenzyme identification and pathogenic characteristics of Leishmania isolated from natural foci of cutaneous leishmaniasis in the USSR. Med Parasit i Parazitol 5:43-48

Strelkova MV, Shurkhal AV, Kelina OI et al (1990b) A new species of Leishmania isolated from the great gerbil Rhombomys opimus. Parasitology 101:327-335

Strelkova MV, Pacheco RS, Bulat SA et al (1997) Comparison of some molecular-genetic techniques for identification of Leishmania circulating in natural foci of zoonotic cutaneous leishmaniasis in the central Asia region. Mem Inst Oswaldo Cruz 92:109-114

Vray B (1998) Biologie cornparée des interactions entre les macrophages et Trypanosoma cruzi. Leishmania spp. et Toxoplasma gondii. Ann Biol 78:221-232

Weigle KA, Labrada LA, Lozano C et al (2002) PCR-based diagnosis of acute and chronic cutaneous leishmaniasis caused by Leishmania (Viannia). J Clin Microbiol 40:601-606 